Review

\title{
Cytokinesis-Block Micronucleus Cytome Assay Evolution into a More Comprehensive Method to Measure Chromosomal Instability
}

\author{
Michael Fenech 1,2,3 \\ 1 Genome Health Foundation, North Brighton, SA 5048, Australia; michael.fenech@unisa.edu.au \\ 2 Centre for Healthy Aging and Wellness, Faculty of Health Science, Universiti Kebangsaan Malaysia, \\ Jalan Raja Muda Abdul Aziz, Kuala Lumpur 50300, Malaysia \\ 3 University of South Australia, School of Pharmacy and Medical Sciences, Adelaide, SA 5000, Australia
}

Received: 8 September 2020; Accepted: 9 October 2020; Published: 15 October 2020

\begin{abstract}
This review describes the cytokinesis-block micronucleus (CBMN) cytome assay and its evolution into a molecular cytogenetic method of chromosomal instability (CIN). Micronuclei (MNi) originate from whole chromosomes or chromosome fragments that fail to segregate to the poles of the cell during mitosis. These lagging chromosomes are excluded from the daughter nuclei and are enveloped in their own membrane to form MNi. The CBMN assay was developed to allow $\mathrm{MNi}$ to be scored exclusively in once-divided binucleated cells, which enables accurate measurement of chromosome breakage or loss without confounding by non-dividing cells that cannot express MNi. The CBMN assay can be applied to cell lines in vitro and cells such as lymphocytes that can be stimulated to divide ex vivo. In the CBMN assay, other CIN biomarkers such as nucleoplasmic bridges (NPBs) and nuclear buds (NBUDs) are also measured. Use of centromere, telomere, and chromosome painting probes provides further insights into the mechanisms through which $\mathrm{MNi}$, NPBs and NBUDs originate. Measurement of MNi is also important because entrapment within a micronucleus may cause chromosomes to shatter and, after nuclear reintegration, become rearranged. Additionally, leakage of DNA from MNi can stimulate inflammation via the cyclic GMP-AMP Synthase-Stimulator of Interferon Genes (cGAS-STING) DNA sensing mechanism of the innate immune system.
\end{abstract}

Keywords: micronucleus; nucleoplasmic bridge; nuclear bud; cytokinesis-block; cytome; chromosomal instability; cGAS-STING

\section{Background}

Interest is growing in high-content assays that can reliably measure chromosomal instability (CIN) because of its important role in causing developmental defects, cancer, and accelerated aging [1-4]. Chromosomal aberrations can be measured directly using metaphase analysis of chromosomes or indirectly by interphase cytogenetic techniques that analyse the DNA content of nuclei and abnormalities of their morphology. One of the most prominent of these nuclear aberrations are micronuclei (MNi), which were discovered more than 100 years ago. This brief review explains the origin of $\mathrm{MNi}$ and the evolution of their measurement, together with other nuclear anomalies, into a multi-endpoint assay of CIN. 


\section{The Origin of Micronuclei}

In 1902, Theodor Boveri (and David Hansemann before him) proposed the following hypothesis: "A malignant tumour cell is a cell with a specific abnormal chromosome constitution." [5]. Boveri also suggested the hypothesis that abnormal chromosome numbers are due to mitotic errors:

"Nonetheless, I regard irregularities of mitosis as the usual way in which a nucleus of inappropriate composition is generated. I would like to say a few more words about this. So-called asymmetrical mitoses, which do not appear to be rare, may have much the same effect as multipolar mitoses. Asymmetrical mitoses, as the analysis of suitable material has shown, arise when the fibres associated with one of the two centrospheres do not form an attachment to all the chromosomes. The chromosomes that are attached to only one set of fibres-or, if division of the chromosome has already begun, the two unseparated daughter chromosomes - then pass to one of the daughter cells, whereas the other daughter cell remains devoid of these elements. It is precisely these aberrations that can easily lead to a marked numerical excess of one type of chromosome relative to the others, if that is what is required." [5]

Boveri's hypotheses have been proven to be correct, especially with regards to the central role of chromosomal instability and aneuploidy in cancer. However, in those early years, there was no reported appreciation that chromosome mal-segregation during mitosis may also result in whole chromosomes or chromosome fragments being left outside the daughter nuclei and isolated from them by the formation of their own nuclear membrane (or "nuclear envelope") to form $\mathrm{MNi}$. MNi were first reported in red blood cells (RBCs) more than 100 years ago by haematologists Howell and Jolly and are also known as Howell-Jolly bodies [6]. They were shown to be increased in splenectomised subjects with megaloblastic anaemia, sickle cell anaemia, in those exposed to ionising radiation, and those with folate and/or vitamin B-12 deficiency [7-9].

$\mathrm{MNi}$ in RBCs originate in the dividing normoblast precursor cells in the bone marrow. The nucleus in the normoblast is ejected during the $\mathrm{RBC}$ maturation process but $\mathrm{MNi}$ are retained. The RBCs with or without MNi leave the bone marrow and enter the peripheral bloodstream. Measurement of $\mathrm{MNi}$ in RBCs in the bone marrow and peripheral blood has become one of the most widely used tests for measuring genotoxicity in rodents and humans $[10,11]$. Eventually, it became evident that $\mathrm{MNi}$ are also expressed in bone marrow precursors of leukocytes and peripheral blood lymphocytes [12].

The use of peripheral blood lymphocytes has the distinct advantage that they can be studied in vivo as well as ex vivo and in in vitro assays because of the availability of well-developed techniques to stimulate lymphocytes to divide with mitogens, which enables the expression of MNi caused by mitotic errors and structural damage to DNA [13-15]. Consequently, the measurement of $\mathrm{MNi}$ in lymphocytes has become one of the most widely applied genotoxicity testing methods for use with human cells both for in vitro genotoxicity testing and for human biomonitoring of exposure to genotoxins [16-22].

Several recent reviews have been written on the detailed mechanisms by which damage to DNA and the mitotic machinery can cause micronucleus $(\mathrm{MN})$ formation and generate genome chaos [15,20,23-26]. There are essentially six main causes for increase in MN formation: (i) genetic defects in the proteins required for mitosis and its checkpoints, (ii) genetic defects in DNA repair enzymes, (iii) excessive exposure to chemical genotoxins, (iv) excessive exposure to ionising radiation, (v) excessive endogenous genotoxins generated by stressed metabolic processes, and (vi) deficiency in the micronutrients required as cofactors for DNA replication and repair. Combinations of these causes of MN formation are likely to occur simultaneously, resulting in either additive or synergistic effects. Figure 1 provides examples of the multiple mechanisms by which genotoxins may induce lesions in DNA and the mitotic apparatus that lead to formation of $\mathrm{MNi}$ and other nuclear anomalies. 


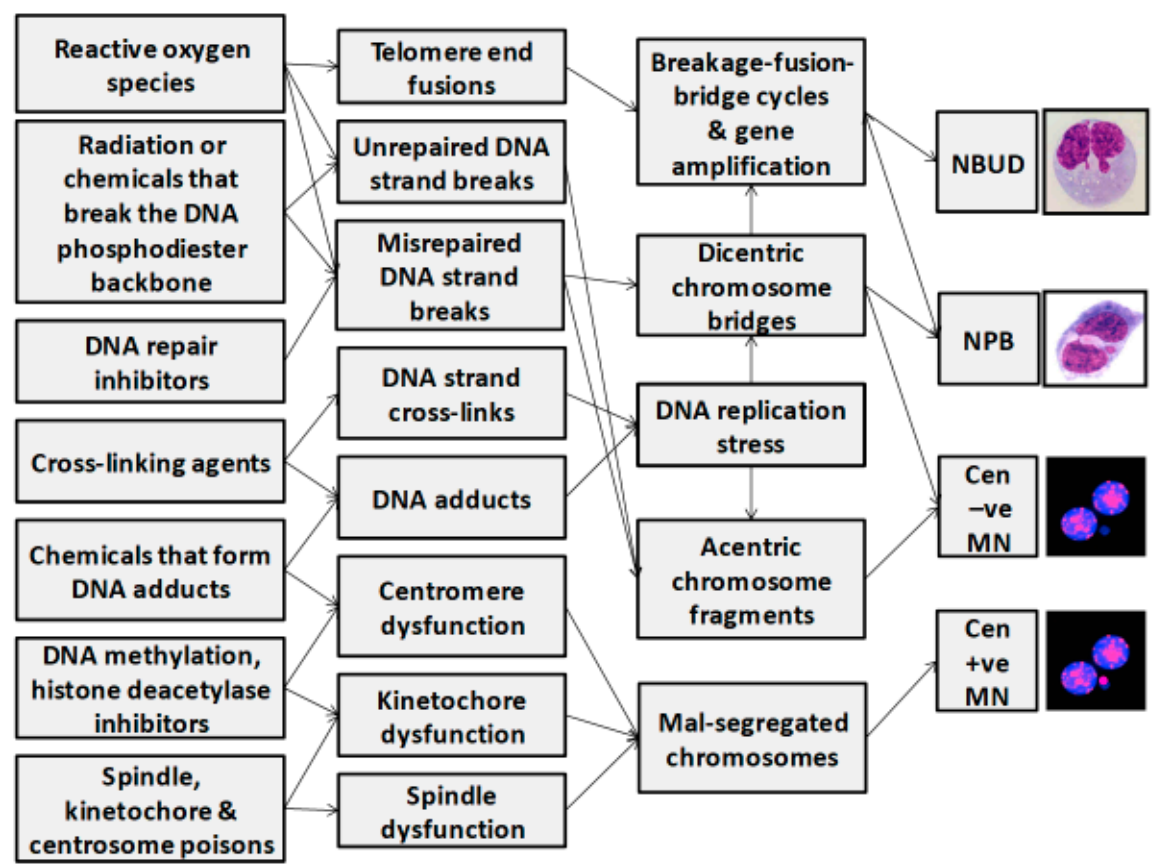

Figure 1. Molecular mechanisms that lead to the formation of micronuclei (MNi), nucleoplasmic bridges (NPBs), and nuclear buds (NBUDs) in lymphocytes. Cen +ve, centromere positive; Cen -ve, centromere negative.

\section{The Cytokinesis-Block Micronucleus Assay}

The expression of chromosome abnormalities as MNi requires completion of nuclear division, but prototype in vivo and in vitro MN assays do not distinguish between non-divided and divided cells. As a consequence, the results obtained by such methods are not reliable because the proportion of cells that complete nuclear division, and are therefore capable of expressing $\mathrm{MNi}$, varies depending on culture conditions, biological age of the cells, and cytostatic or proliferative effects of the cytotoxic or genotoxic agent investigated that could delay mitotic progression or induce apoptotic cell death $[27,28]$. There was therefore a need to further develop the MN assay so that MNi could be scored specifically in cells that completed nuclear division. Different methods to achieve this were attempted but the one that was most reliable and adopted worldwide was the cytokinesis-block technique originally reported by Fenech and Morley [29]. In the cytokinesis-block micronucleus (CBMN) assay, cells that have completed nuclear division are accumulated and identified by their binucleated (BN) appearance after inhibiting the formation of the actin microfilament ring required for cytokinesis (Figure 2). Inhibition of cytokinesis and accumulation of $\mathrm{BN}$ cells is generally achieved by treating cell cultures with 3.0-6.0 $\mu \mathrm{g} / \mathrm{mL}$ cytochalasin-B (Cyt-B) for 24-30 h. The concentration of Cyt-B and the duration of its treatment should be optimised for each cell type so that the frequency of $\mathrm{BN}$ cells is maximised. The latter is important for efficient scoring of $\mathrm{MNi}$ in $\mathrm{BN}$ cells. 
Micronucleus formation due to chromosome mal-segregation or unrepaired beaks
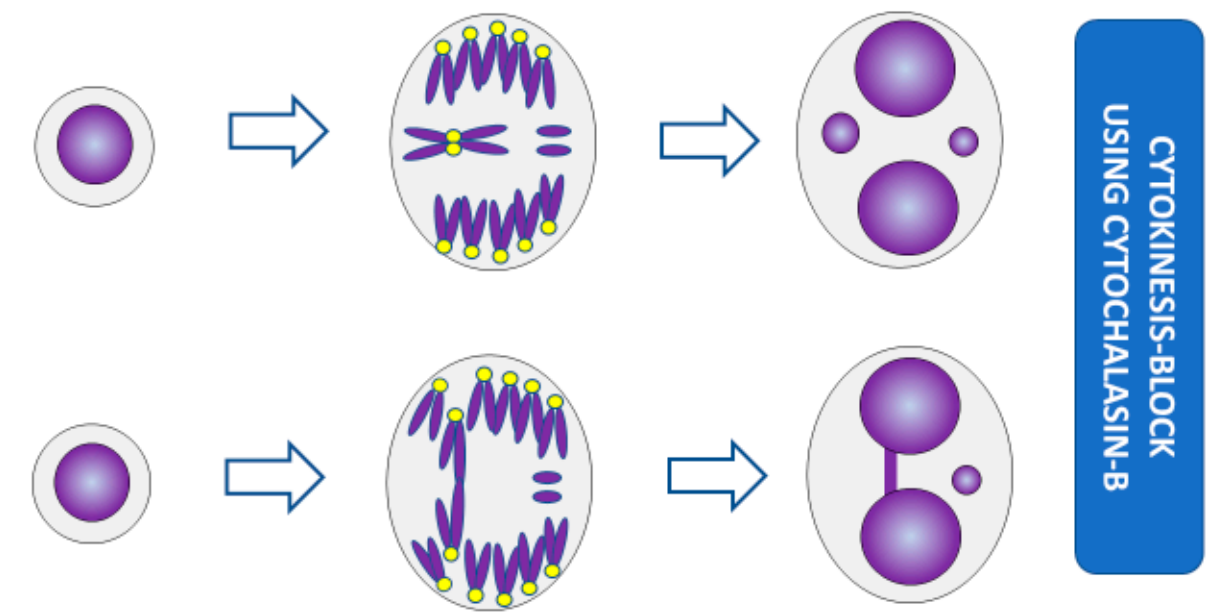

Nucleoplasmic bridge and micronucleus formation due to DNA strand break mis-repair, incomplete chromatid separation or telomere end-fusion

Figure 2. Formation of micronuclei and nucleoplasmic bridges in cytokinesis-blocked cells. (For the sake of simplicity, the conceptual diagrams only show a representative fraction of chromosomes.) Yellow dots represent centromeres. The acentric fragments in the bottom panel are generated during mis-repair of DNA strand breaks but not during incomplete chromatid separation or telomere end-fusion.

\section{The CBMN Cytome Assay to Measure Chromosomal Instability}

Shortly after the invention of the CBMN assay, it became evident that, apart from the exclusive scoring of MNi in cells that completed nuclear division, there were other advantages to using the cytokinesis-block method:

1. Blocking of cells in the binucleated cell stage allowed the efficient measurement of the formation of nucleoplasmic bridges (NPBs) that originate from dicentric chromosomes caused by telomere end-fusions or mis-repair of DNA breaks or failure of complete chromatid separation (Figures 2-6) [13,20,23,30,31].

2. Nuclei in BN cells form nuclear buds (NBUDs), which are another indicator of chromosomal instability as they are a mechanism through which nuclei eliminate amplified genes and unresolved DNA repair complexes (Figures 3 and 4) [32-34].

3. The ability to score MNi, NPBs, and NBUDs within the same cells made it possible to reliably test the relationship between these biomarkers of chromosomal instability and discover that they are highly correlated with each other and represent the cytogenetic phenotype of bridge-breakage-fusion cycles that are initiated by the formation of dicentric chromosomes and cause gene amplification (Figures 2-5) [30,31,35,36].

4. The ratios of mononucleated (MONO) cells, BN cells, and multi-nucleated (MULTI) cells with more than two nuclei (Figure 4) provided an index of cell proliferation and cytostasis [13]. 


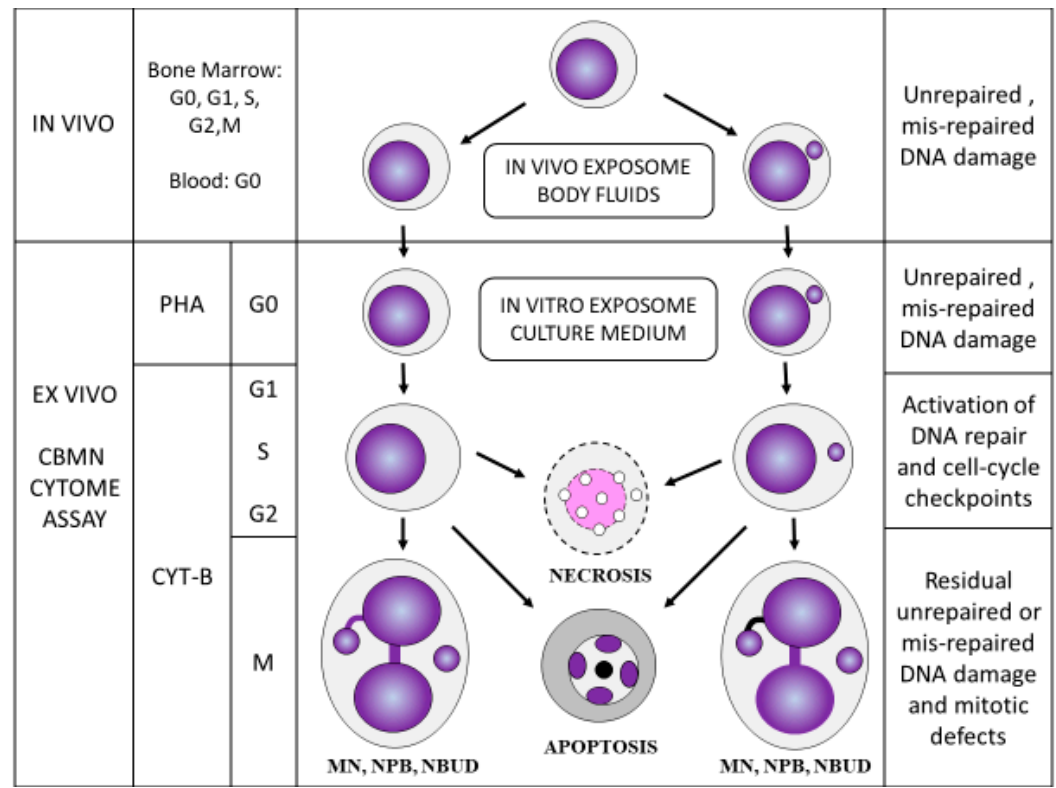

Figure 3. The main features of the lymphocyte cytokinesis-block micronucleus cytome (CBMNcyt) assay. G0, G1, S, G2, and M represent the various stages of the nuclear division cycle following stimulation using the mitogen phytohaemagglutinin (PHA). CYT-B, cytochalasin-B, which is used to block cells that complete nuclear division at the binucleated stage. MN, micronucleus; NPB, nucleoplasmic bridge; NBUD, nuclear bud. This figure is a copy of Figure 3 in Kirsch-Volders et al. [37]. Permission to re-use this figure was obtained from the publisher Elsevier.

\section{CBMN CYTOME ASSAY}

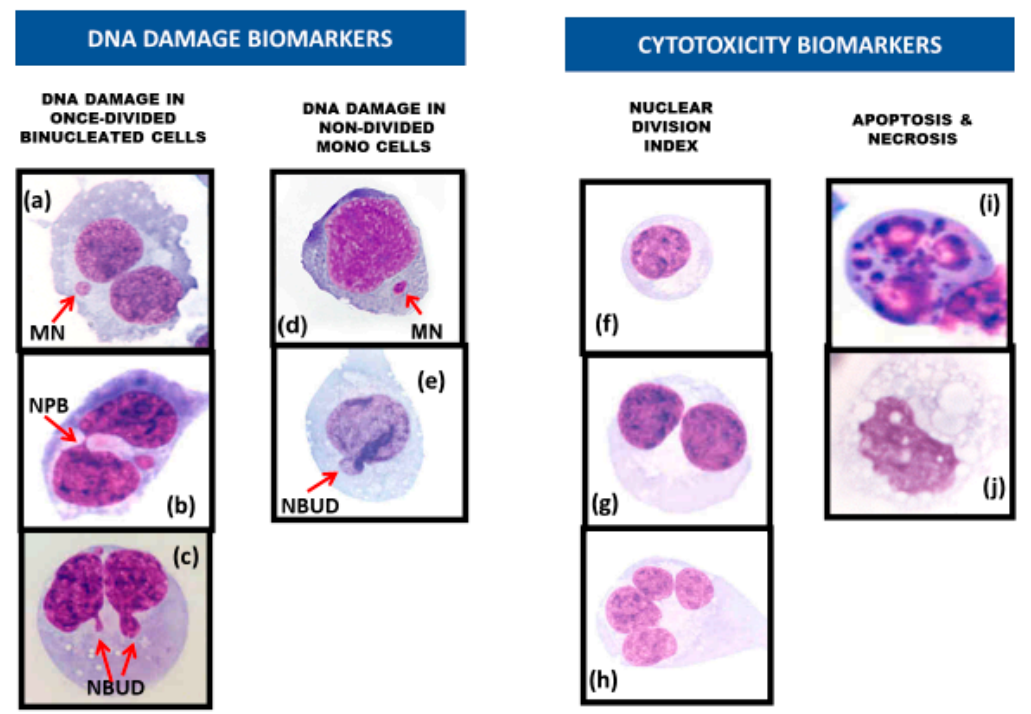

Figure 4. DNA damage and cytotoxicity biomarkers in the lymphocyte cytokinesis-block micronucleus cytome (CBMN-Cyt) assay. DNA damage biomarkers include (a) binucleated (BN) cells with a micronucleus (MN), (b) BN cells with a nucleoplasmic bridge (NPB), (c) BN cells with a nuclear bud (NBUD), (d) mononucleated (MONO) cells with a MN, and (e) MONO cells with a NBUD. Cytotoxicity biomarkers include the relative frequencies of (f) MONO cells, (g) BN cells, and (h) multi-nucleated cells with three or more nuclei, which together are used to measure the nuclear division index, a measure of cytostatic effects. In addition, $(\mathbf{i})$ apoptotic cells and $(\mathbf{j})$ necrotic cells are scored to obtain a measure of total cell death and the type of cell death. This figure has been adapted from Figure 1 in Rodrigues et al. [38]. Permission was obtained from the publisher Elsevier. 


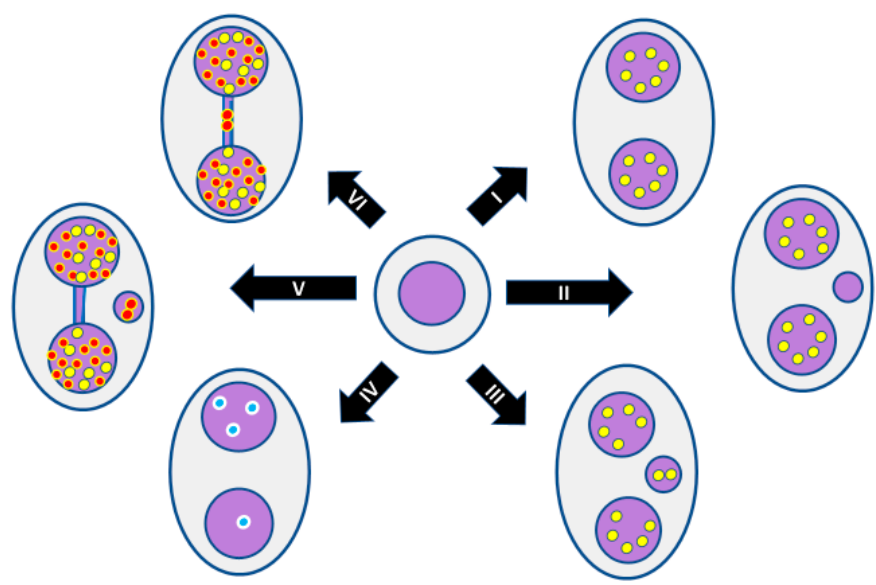

Figure 5. Use of molecular probes in the CBMN cytome assay to understand mechanisms: (I) normal binucleated (BN) cell; (II) BN cell containing one micronucleus originating from an acentric chromosome fragment; (III) BN cell containing one micronucleus originating from a mal-segregated whole chromosome; (IV) Mal-segregation of a chromosome in a BN cell without a micronucleus, which is evident because of unequal distribution of chromosome-specific peptide nucleic acid (PNA) probe signals; (V) BN cell with a nucleoplasmic bridge and micronucleus originating from a dicentric chromosome and an acentric chromosome fragment as a result of mis-repair of DNA strand breaks; (VI) BN cell with a nucleoplasmic bridge only, originating from a dicentric chromosome as a result of fusion of the telomeres of two chromosomes. Yellow dots represent signals observed using pancentromeric PNA probes. Red dots represent signals observed using telomere PNA probes. Blue dots represent signals observed using a PNA probe specific to only one chromosome. For the sake of simplicity, the conceptual diagrams only show a representative fraction of chromosomes.

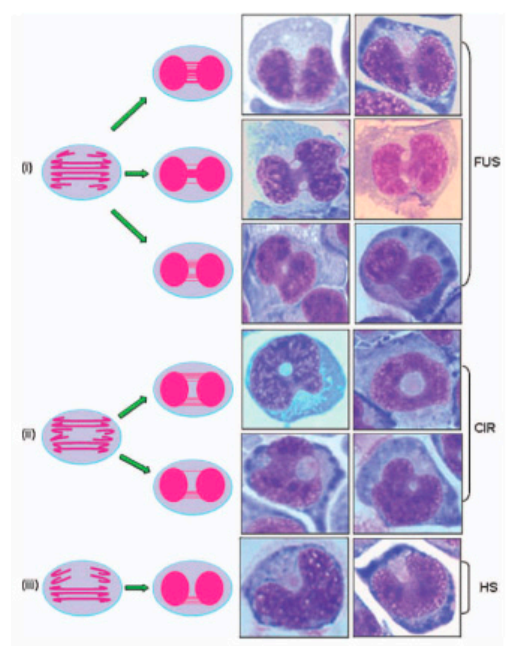

Figure 6. Typical appearances of the additional nuclear anomalies observed in the CBMN-Cyt assay. The nuclear anomalies: (i) fused (FUS), (ii) circular (CIR), or (iii) horseshoe (HS) nuclei. In the proposed models: (i) FUS nuclei originate as a result of multiple nuclear strands occurring uniformly or centrally between the nuclei of a binucleated (BN) cell, (ii) CIR nuclei originate as a result of multiple nuclear strands occurring on opposite sides between the nuclei of a BN cell, and (iii) HS nuclei originate as a result of multiple nuclear strands occurring only on one side between the nuclei of a BN cell. In each of these models, the total combined width of the connections between the nuclei in a BN cell is typically larger than one-fourth of the nuclear diameter-the maximum width of a conventional NPB, as defined within the CBMN-Cyt assay [13]. For the sake of simplicity, the conceptual diagrams only show a representative fraction of chromosomes. This figure was reproduced from Bull et al. [31], with permission from Wiley Periodicals, Inc. 
In addition, it became evident that necrotic and apoptotic cells (Figure 4) could be easily identified using a simple set of scoring criteria so that the frequency and mechanism of cell death could also be efficiently measured and considered as an important factor in the toxicological assessment of the tested conditions.

\section{Use of Molecular Probes in the CBMN Cytome Assay to Understand the Mechanisms}

Molecular probes can further interrogate cells in the CBMN cytome assay to elucidate the mechanism of the formation of MNi, NPBs and NBUDs [39-43]. For example, pancentromere peptide nucleic acid (PNA) probes are now often used to determine whether $\mathrm{MNi}$ originated from an acentric chromosome fragment or a whole chromosome loss event, which would be centromere-negative and centromere-positive, respectively (Figure 5II,III) [39,40]. Furthermore, by using chromosome-specific PNA probes, it is possible to test, even in BN cells without a MN, whether non-disjunction of a specific chromosome has occurred by, for example, a distribution of the probe signal of 3:1 instead of 2:2 among the daughter nuclei (Figure 5IV) [41].

Telomere probes can also be used together with centromere probes. A MN that is telomere-positive but centromere-negative contains an acentric chromosome fragment and its associated telomere; in such an event, one of the daughter nuclei from the same mitosis will consequently have a defective chromosome that lacks the fragment and telomere trapped in the MN (Figure 5V). An NPB that is telomere-positive in the bridge region between centromeres most likely originates from telomere end-fusion (Figure 5VI), whereas an NPB that is telomere-negative in the bridge region (Figure 5V) is probably the result of mis-repair of sub-telomeric DNA breaks involving two chromosomes, which generates a dicentric chromosome and an acentric chromosome fragment that is telomere-positive; the latter results in formation of a telomere-positive MN. Using telomere and centromere probes, it is possible to determine the origin of MNi and NBUDs induced by folate deficiency [42], with MNi being primarily derived from lagging chromosomes $(22.0 \%)$ and terminal acentric fragments $(62.2 \%)$, whereas most NBUDs originate mainly from interstitial fragments (42.7\%) or terminal acentric fragments $(43.5 \%)$.

\section{Other Emerging Biomarkers in the CBMN Cytome Assay}

Other nuclear anomalies can be observed in cells with chromosomal instability, but these have not yet been adequately validated. For example, we have identified additional nuclear anomalies formed under folate-deficient conditions, defined as fused (FUS), circular (CIR), and horseshoe (HS) nuclei, and investigated their suitability for inclusion as additional CIN biomarkers in the lymphocyte cytokinesis-block micronucleus cytome (CBMN-Cyt) assay (Figure 6) [31,44]. Although the morphological appearance of FUS, CIR, and HS nuclei suggested an origin from multiple NPBs in the fusion region between the two nuclei, the low frequency of dicentric chromosomes in the metaphase spreading from these cultures did not support this model [31]. Fluorescence in situ hybridization (FISH) analysis of cytokinesis-blocked binucleated (BN) cells with peptide nucleic acid probes for telomeres and centromeres (PNA-FISH) revealed a high proportion of fusion regions containing both centromeric and telomeric DNA. This suggested that folate deficiency may disrupt the process of sister chromatid separation and chromosome segregation during mitosis. It was concluded that the FUS, CIR, and HS morphologies represent promising biomarkers of CIN that are sensitive to folate deficiency. Further validation and investigation of the mechanisms responsible for their formation is warranted. 
Reports have recently emerged indicating that mutations in genes that affect cohesin, condensin, and separase functions, which control chromatid separation during mitosis, cause multiple anaphase bridges similar to those that may result in formation of FUS, CIR, and HS nuclei [45-48]. Furthermore, a proportion of the multiple narrow bridges observed between the nuclei of FUS cells may also be ultra-fine bridges (UFBs), which can arise from DNA catenanes at centromeres/rDNA loci, late replication intermediates induced by replication stress, and DNA linkages at telomeres [49]. However, this has not been previously tested and would require the detection of proteins that specifically bind UFBs, including Bloom's syndrome helicase (BLM), PLK1-interacting checkpoint helicase (PICH) and replication protein A (RPA), to verify their involvement [49].

\section{Shattering of Chromosomes in MNi and Their Subsequent Hypermutation and Inflammation}

Another important recent development regarding the consequences of $\mathrm{MN}$ formation is the observation that entrapment of chromosomes in MNi may result in premature chromosome condensation of the chromosome and its fragmentation. This situation occurs when DNA replication in the $\mathrm{MN}$ is delayed relative to the nucleus [50-56]. The resulting chromosome fragments may be incorporated into one of the daughter nuclei and undergo error-prone repair by non-homologous end joining, resulting in a massively rearranged mutant chromosome [52,53,57-60]. Therefore, it is evident that $\mathrm{MNi}$ are not only biomarkers of induced chromosomal instability but also a cause of further amplification of chromosomal instability that can occur in just two cell cycles.

One of the reasons for delayed DNA replication in MNi could be because of DNA replication stress resulting from lack of the enzymes and cofactors required for DNA synthesis and repair. This may be due to defective nuclear envelope assembly of MNi resulting in a lack of nuclear pore complexes; consequently, MNi fail to properly import key proteins that are necessary for the integrity of the nuclear envelope and the genome [54,61-63]. Disruption of the MN membrane may also either result in leakage of DNA into the cytoplasm and/or provide access for cytoplasmic DNAases to attack the DNA in MNi $[54,62,63]$. There is now a substantial body of evidence that DNA from MNi can be sensed by the innate immune system via cyclic GMP-AMP synthase (cGAS), which generates Cyclic guanosine monophosphate-adenosine monophosphate (cGAMP), which in turn activates Stimulator of Interferon Genes (STING), resulting in increased expression of interferon and activation of pro-inflammatory interferon-stimulated genes [64-67]. The induced inflammation, if left unresolved, can subsequently increase oxidative stress and further aggravate chromosomal instability, resulting in a vicious cycle of $\mathrm{MNi}$, NPBs, NBUD formation, hypermutation, and increasing inflammation.

Methods to measure the pulverisation of chromosomes trapped in $\mathrm{MNi}$, defective membranes in disrupted $\mathrm{MNi}$, cGAS positive $\mathrm{MNi}$, and leakage of DNA into the cytoplasm in cells containing $\mathrm{MNi}$ have been recently published [50-67].

Figure 7 summarises the key steps in MNi formation, the pulverisation of chromosomes entrapped in $\mathrm{MNi}$, and the consequent steps of either hypermutation of the trapped chromosome and/or the triggering of inflammation by the cGAS-STING mechanism. 


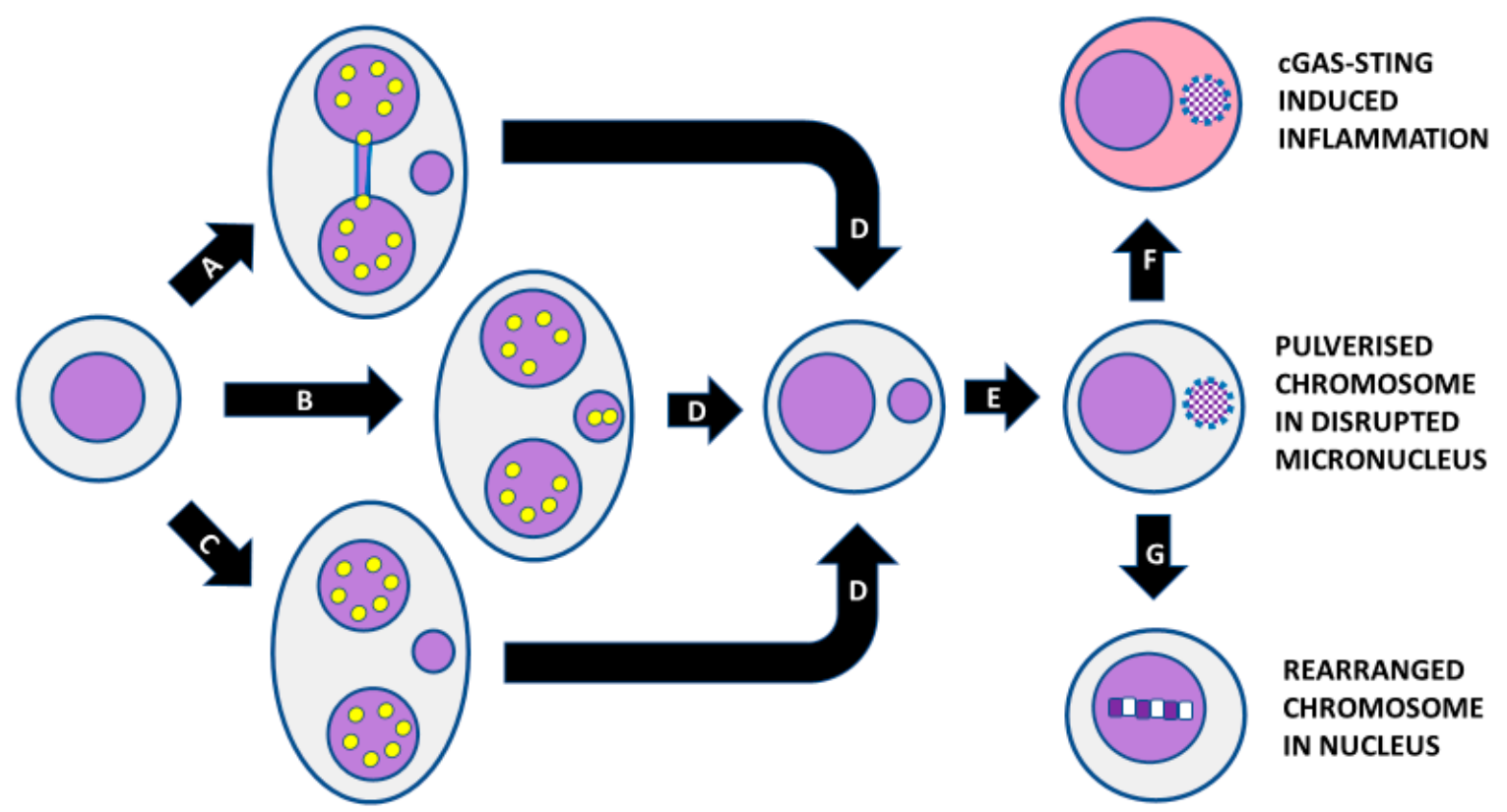

Figure 7. Consequences of micronucleus formation. Micronucleus formation at the binucleated cell stage as a result of (A) mis-repair of DNA breaks leading to a nucleoplasmic bridge and an acentric chromosome fragment, (B) the whole chromosome as a result of mal-segregation, and (C) lagging acentric chromosome fragments as a result of unrepaired DNA breaks. (D) Mononuclear cell with a micronucleus after completion of cytokinesis. (E) Shattering of chromosomes trapped in a micronucleus and disruption of the nuclear envelope of the micronucleus. (F) Leakage of DNA from the micronucleus, leading to activation of cyclic GMP-AMP synthase-Stimulator of Interferon Genes (cGAS-STING) mechanism and induction of inflammatory cytokines. (G) Integration of pulverised chromosomes within the main nucleus and error-prone repair by non-homologous end-joining, resulting in a greatly rearranged mutant chromosome. Yellow dots represent centromeres.

\section{Conclusions and Future Directions}

The CBMN cytome assay is a multi-endpoint cytogenetic technique that enables measurement of several nuclear anomalies indicative of many aspects of CIN, which include structural/numerical chromosome aberrations and chromosome mal-segregation during mitosis expressed as $\mathrm{MNi}$, anaphase bridge formation expressed as NPBs, and gene amplification or elimination of unresolved DNA complexes expressed as NBUDs.

Mechanistic information about the origin of MNi, NPBs. and NBUDs can be obtained by the additional use of molecular probes such as those that detect the presence of centromeres, telomeres, and DNA damage response proteins.

The consequences of chromosome entrapment within $\mathrm{MNi}$ are chromothripsis caused by premature chromosome condensation in later replicating $\mathrm{MNi}$ and chromoanagenesis due to error-prone repair of the resulting shattered chromosomes.

The additional consequence of MNi formation is stimulation of the innate immune system's cGAS-STING pathway, which further increases the importance of MNi formation as a biomarker of cellular malfunction and as a driver of degenerative diseases that increase with age.

In view of the above, it is important that future research addresses the following questions:

(1) What are the preventable causes of MNi, NPBs, and NBUD formation?

(2) What are the most important genetic causes of MNi, NPBs, and NBUD formation?

(3) Are cGAS-STING induction and chromoanagenesis mutually exclusive or do they occur one after the other in the same cell? 
(4) What are the molecular differences between $\mathrm{MNi}$ that remain extranuclear and trigger cGAS-STING versus MNi that result in chromothripsis followed by nuclear reintegration and chromoanagenesis?

(5) What are the best probes to detect chromosome pulverisation in $\mathrm{MNi}$, induction of cGAS-STING by $\mathrm{MNi}$, and chromoanagenesis of a pulverised chromosome within a nucleus?

(6) Is it possible to further enhance the lymphocyte CBMN cytome assay by automation so that it becomes practical to use it as a high-content molecular cytogenetic assay using multiple probes simultaneously not only as a research tool to study mechanisms but also in routine clinical diagnostics of healthy aging?

Funding: This research did not receive external funding.

Conflicts of Interest: The author declares no conflict of interest.

\begin{tabular}{ll}
\multicolumn{2}{l}{ Abbreviations } \\
BN & binucleated \\
CBMN & cytokinesis-block micronucleus \\
cGAS & cyclic GMP-AMP synthase \\
CIN & chromosomal instability \\
FISH & fluorescence in situ hybridisation \\
MN & micronucleus \\
MNi & micronuclei \\
NBUDs & nuclear buds \\
NPBs & nucleoplasmic bridges \\
PNA & peptide nucleic acid \\
RBCs & red blood cells \\
STING & Stimulator of Interferon Genes \\
UFBs & ultra-fine bridges
\end{tabular}

\section{References}

1. Daughtry, B.L.; Chavez, S.L. Chromosomal instability in mammalian pre-implantation embryos: Potential causes, detection methods, and clinical consequences. Cell Tissue Res. 2016, 363, 201-225. [CrossRef] [PubMed]

2. Bakhoum, S.F.; Cantley, L.C. The Multifaceted Role of Chromosomal Instability in Cancer and Its Microenvironment. Cell 2018, 174, 1347-1360. [CrossRef] [PubMed]

3. Barroso-Vilares, M.; Logarinho, E. Chromosomal instability and pro-inflammatory response in aging. Mech. Ageing Dev. 2019, 182, 111118. [CrossRef] [PubMed]

4. Rao, C.V.; Asch, A.S.; Yamada, H.Y. Emerging links among Chromosome Instability (CIN), cancer, and aging. Mol. Carcinog. 2017, 56, 791-803. [CrossRef]

5. Boveri, T. Concerning the origin of malignant tumours by Theodor Boveri. Translated and annotated by Henry Harris. J. Cell Sci. 2008, 121 (Suppl. 1), 1-84. [CrossRef]

6. Sears, D.A.; Udden, M.M. Howell-Jolly bodies: A brief historical review. Am. J. Med. Sci. 2012, 343, 407-409. [CrossRef]

7. Bain, B.J. Prominent Howell-Jolly bodies when megaloblastic anemia develops in a hyposplenic patient. Am. J. Hematol. 2014, 89, 852. [CrossRef]

8. Everson, R.B.; Wehr, C.M.; Erexson, G.L.; MacGregor, J.T. Association of marginal folate depletion with increased human chromosomal damage in vivo: Demonstration by analysis of micronucleated erythrocytes. J. Natl. Cancer Inst. 1988, 80, 525-529. [CrossRef]

9. Dawson, D.W.; Bury, H.P. The significance of Howell-Jolly bodies and giant metamyelocytes in marrow smears. J. Clin. Pathol. 1961, 14, 374-380. [CrossRef]

10. Heddle, J.A.; Fenech, M.; Hayashi, M.; MacGregor, J.T. Reflections on the development of micronucleus assays. Mutagenesis 2011, 26, 3-10. [CrossRef] 
11. Hayashi, M.; Tice, R.R.; MacGregor, J.T.; Anderson, D.; Blakey, D.H.; Kirsh-Volders, M.; Oleson, F.B., Jr.; Pacchierotti, F.; Romagna, F.; Shimada, H. In vivo rodent erythrocyte micronucleus assay. Mutat. Res. 1994, 312, 293-304. [CrossRef]

12. Odagiri, Y.; Takemoto, K.; Fenech, M. Micronucleus induction in cytokinesis-blocked mouse bone marrow cells in vitro following in vivo exposure to X-irradiation and cyclophosphamide. Environ. Mol. Mutagen 1994, 24, 61-67. [CrossRef] [PubMed]

13. Fenech, M. Cytokinesis-block micronucleus cytome assay. Nat. Protoc. 2007, 2, 1084-1104. [CrossRef] [PubMed]

14. Fenech, M.; Perepetskaya, G.; Mikhalevich, L. A more comprehensive application of the micronucleus technique for biomonitoring of genetic damage rates in human populations-Experiences from the Chernobyl catastrophe. Environ. Mol. Mutagen 1997, 30, 112-118. [CrossRef]

15. Fenech, M.; Knasmueller, S.; Bolognesi, C.; Bonassi, S.; Holland, N.; Migliore, L.; Palitti, F.; Natarajan, A.T.; Kirsch-Volders, M. Molecular mechanisms by which in vivo exposure to exogenous chemical genotoxic agents can lead to micronucleus formation in lymphocytes in vivo and ex vivo in humans. Mutat. Res. 2016, 770 Pt A, 12-25. [CrossRef]

16. Kirsch-Volders, M.; Fenech, M.; Bolognesi, C. Validity of the Lymphocyte Cytokinesis-Block Micronucleus Assay (L-CBMN) as biomarker for human exposure to chemicals with different modes of action: A synthesis of systematic reviews. Mutat. Res. Genet. Toxicol. Environ. Mutagen 2018, 836 Pt A, 47-52. [CrossRef]

17. Kirsch-Volders, M.; Fenech, M. Micronucleus Assays with Human Lymphocytes for In Vitro Genetic Toxicology Testing. In The Micronucleus Assay in Toxicology; Knasmüller, S., Fenech, M., Eds.; The Royal Society of Chemistry: London, UK, 2019; pp. 157-168.

18. Kirsch-Volders, M.; Decordier, I.; Elhajouji, A.; Plas, G.; Aardema, M.J.; Fenech, M. In vitro genotoxicity testing using the micronucleus assay in cell lines, human lymphocytes and 3D human skin models. Mutagenesis 2011, 26, 177-184. [CrossRef] [PubMed]

19. OECD. Test No. 487: In Vitro Mammalian Cell Micronucleus Test; OECD Publishing: Paris, France, 2014. [CrossRef]

20. Fenech, M. The lymphocyte cytokinesis-block micronucleus cytome assay and its application in radiation biodosimetry. Health Phys. 2010, 98, 234-243. [CrossRef]

21. International Atomic Energy Agency. Cytogenetic Dosimetry: Applications in Preparedness for and Response to Radiation Emergencies; International Atomic Energy Agency: Vienna, Austria, 2011.

22. ISO 17099. Radiological Protection-Performance Criteria for Laboratories Using the Cytokinesis Block Micronucleus (CBMN) Assay in Peripheral Blood Lymphocytes for Biological Dosimetry. 2014. Available online: https://www.iso.org/standard/59141.html (accessed on 30 November 2014).

23. Fenech, M.; Kirsch-Volders, M.; Natarajan, A.T.; Surralles, J.; Crott, J.W.; Parry, J.; Norppa, H.; Eastmond, D.A.; Tucker, J.D.; Thomas, P. Molecular mechanisms of micronucleus, nucleoplasmic bridge and nuclear bud formation in mammalian and human cells. Mutagenesis 2011, 26, 125-132. [CrossRef]

24. Fenech, M.F. Dietary reference values of individual micronutrients and nutriomes for genome damage prevention: Current status and a road map to the future. Am. J. Clin. Nutr. 2010, 91, 1438S-1454S. [CrossRef]

25. Fenech, M. Perspectives in Nutrigenomics and Nutrigenetics. Sight Life 2015, 29, 64-70.

26. Ye, C.J.; Sharpe, Z.; Alemara, S.; Mackenzie, S.; Liu, G.; Abdallah, B.; Horne, S.; Regan, S.; Heng, H.H. Micronuclei and Genome Chaos: Changing the System Inheritance. Genes 2019, 1, 366. [CrossRef] [PubMed]

27. Fenech, M. A mathematical model of the in vitro micronucleus assay predicts false negative results if micronuclei are not specifically scored in binucleated cells or in cells that have completed one nuclear division. Mutagenesis 2000, 15, 329-336. [CrossRef] [PubMed]

28. Fenech, M.; Morley, A.A. Cytokinesis-block micronucleus method in human lymphocytes: Effect of in vivo ageing and low dose X-irradiation. Mutat. Res. 1986, 161, 193-198. [CrossRef]

29. Fenech, M.; Morley, A.A. Measurement of micronuclei in lymphocytes. Mutat. Res. 1985, 147, $29-36$. [CrossRef]

30. Thomas, P.; Umegaki, K.; Fenech, M. Nucleoplasmic bridges are a sensitive measure of chromosome rearrangement in the cytokinesis-block micronucleus assay. Mutagenesis 2003, 18, 187-194. [CrossRef]

31. Bull, C.F.; Mayrhofer, G.; Zeegers, D.; Mun, G.L.; Hande, M.P.; Fenech, M.F. Folate deficiency is associated with the formation of complex nuclear anomalies in the cytokinesis-block micronucleus cytome assay. Environ. Mol. Mutagen 2012, 53, 311-323. [CrossRef] 
32. Utani, K.; Okamoto, A.; Shimizu, N. Generation of micronuclei during interphase by coupling between cytoplasmic membrane blebbing and nuclear budding. PLoS ONE 2011, 6, e27233. [CrossRef]

33. Oobatake, Y.; Shimizu, N. Double-strand breakage in the extrachromosomal double minutes triggers their aggregation in the nucleus, micronucleation, and morphological transformation. Genes Chromosomes Cancer 2020, 59, 133-143. [CrossRef]

34. Haaf, T.; Raderschall, E.; Reddy, G.; Ward, D.C.; Radding, C.M.; Golub, E.I. Sequestration of mammalian Rad51-recombination protein into micronuclei. J. Cell Biol. 1999, 144, 11-20. [CrossRef]

35. Fenech, M.; Crott, J.W. Micronuclei, nucleoplasmic bridges and nuclear buds induced in folic acid deficient human lymphocytes-evidence for breakage-fusion-bridge cycles in the cytokinesis-block micronucleus assay. Mutat. Res. 2002, 504, 131-136. [CrossRef]

36. El-Zein, R.A.; Schabath, M.B.; Etzel, C.J.; Lopez, M.S.; Franklin, J.D.; Spitz, M.R. Cytokinesis-blocked micronucleus assay as a novel biomarker for lung cancer risk. Cancer Res. 2006, 66, 6449-6456. [CrossRef] [PubMed]

37. Kirsch-Volders, M.; Bonassi, S.; Knasmueller, S.; Holland, N.; Bolognesi, C.; Fenech, M.F. Commentary: Critical questions, misconceptions and a road map for improving the use of the lymphocyte cytokinesis-block micronucleus assay for in vivo biomonitoring of human exposure to genotoxic chemicals-A HUMN project perspective. Mutat. Res. Rev. Mutat. Res. 2014, 759, 49-58. [CrossRef] [PubMed]

38. Rodrigues, M.A.; Beaton-Green, L.A.; Wilkins, R.C.; Fenech, M.F. The potential for complete automated scoring of the cytokinesis block micronucleus cytome assay using imaging flow cytometry. Mutat. Res. Genet. Toxicol. Environ. Mutagen 2018, 836 Pt A, 53-64. [CrossRef] [PubMed]

39. Decordier, I.; Kirsch-Volders, M. Fluorescence in situ hybridization (FISH) technique for the micronucleus test. Methods Mol. Biol. 2013, 1044, 237-244. [CrossRef]

40. Fucic, A.; Katic, J.; Fthenou, E.; Kogevinas, M.; Plavec, D.; Koppe, J.; Batinic, D.; Chalkiadaki, G.; Chatzi, L.; Lasan, R.; et al. Increased frequency of micronuclei in mononucleated lymphocytes and cytome analysis in healthy newborns as an early warning biomarkers of possible future health risks. Reprod. Toxicol. 2013, 42, 110-115. [CrossRef] [PubMed]

41. Wang, X.; Thomas, P.; Xue, J.; Fenech, M. Folate deficiency induces aneuploidy in human lymphocytes in vitro-evidence using cytokinesis-blocked cells and probes specific for chromosomes 17 and 21. Mutat. Res. 2004, 551, 167-180. [CrossRef] [PubMed]

42. Lindberg, H.K.; Wang, X.; Järventaus, H.; Falck, G.C.; Norppa, H.; Fenech, M. Origin of nuclear buds and micronuclei in normal and folate-deprived human lymphocytes. Mutat. Res. 2007, 617, 33-45. [CrossRef]

43. Zaguia, N.; Laplagne, E.; Colicchio, B.; Cariou, O.; Al Jawhari, M.; Heidingsfelder, L.; Hempel, W.M.; Jrad, B.B.H.; Jeandidier, E.; Dieterlen, A.; et al. A new tool for genotoxic risk assessment: Reevaluation of the cytokinesis-block micronucleus assay using semi-automated scoring following telomere and centromere staining. Mutat. Res. 2020, 850-851, 503143. [CrossRef]

44. Lee, S.L.; Thomas, P.; Fenech, M. Extracellular amyloid $\beta 42$ causes necrosis, inhibition of nuclear division, and mitotic disruption under both folate deficient and folate replete conditions as measured by the cytokinesis-block micronucleus cytome assay. Environ. Mol. Mutagen 2014, 55, 1-14. [CrossRef]

45. Remeseiro, S.; Cuadrado, A.; Carretero, M.; Martínez, P.; Drosopoulos, W.C.; Cañamero, M.; Schildkraut, C.L.; Blasco, M.A.; Losada, A. Cohesin-SA1 deficiency drives aneuploidy and tumourigenesis in mice due to impaired replication of telomeres. EMBO J. 2012, 31, 2076-2089. [CrossRef]

46. Deardorff, M.A.; Wilde, J.J.; Albrecht, M.; Dickinson, E.; Tennstedt, S.; Braunholz, D.; Mönnich, M.; Yan, Y.; Xu, W.; Gil-Rodríguez, M.C.; et al. RAD21 mutations cause a human cohesinopathy. Am. J. Hum. Genet. 2012, 90, 1014-1027. [CrossRef]

47. Martin, C.A.; Murray, J.E.; Carroll, P.; Leitch, A.; Mackenzie, K.J.; Halachev, M.; Fetit, A.E.; Keith, C.; Bicknell, L.S.; Fluteau, A.; et al. Mutations in genes encoding condensin complex proteins cause microcephaly through decatenation failure at mitosis. Genes Dev. 2016, 30, 2158-2172. [CrossRef]

48. Hellmuth, S.; Böttger, F.; Pan, C.; Mann, M.; Stemmann, O. PP2A delays APC/C-dependent degradation of separase-associated but not free securin. EMBO J. 2014, 33, 1134-1147. [CrossRef]

49. Chan, Y.W.; West, S.C. A new class of ultrafine anaphase bridges generated by homologous recombination. Cell Cycle 2018, 17, 2101-2109. [CrossRef]

50. Zhang, C.Z.; Spektor, A.; Cornils, H.; Francis, J.M.; Jackson, E.K.; Liu, S.; Meyerson, M.; Pellman, D. Chromothripsis from DNA damage in micronuclei. Nature 2015, 522, 179-184. [CrossRef] 
51. Lewis, C.W.; Golsteyn, R.M. Cancer cells that survive checkpoint adaptation contain micronuclei that harbor damaged DNA. Cell Cycle 2016, 15, 3131-3145. [CrossRef] [PubMed]

52. Holland, A.J.; Cleveland, D.W. Chromoanagenesis and cancer: Mechanisms and consequences of localized, complex chromosomal rearrangements. Nat. Med. 2012, 18, 1630-1638. [CrossRef]

53. Fukami, M.; Kurahashi, H. Clinical Consequences of Chromothripsis and Other Catastrophic Cellular Events. Methods Mol. Biol. 2018, 176, 21-33. [CrossRef]

54. Liu, S.; Kwon, M.; Mannino, M.; Yang, N.; Renda, F.; Khodjakov, A.; Pellman, D. Nuclear envelope assembly defects link mitotic errors to chromothripsis. Nature 2018, 561, 551-555. [CrossRef] [PubMed]

55. Terzoudi, G.I.; Karakosta, M.; Pantelias, A.; Hatzi, V.I.; Karachristou, I.; Pantelias, G. Stress induced by premature chromatin condensation triggers chromosome shattering and chromothripsis at DNA sites still replicating in micronuclei or multinucleate cells when primary nuclei enter mitosis. Mutat. Res. Genet. Toxicol. Environ. Mutagen 2015, 793, 185-198. [CrossRef] [PubMed]

56. Pantelias, A.; Karachristou, I.; Georgakilas, A.G.; Terzoudi, G.I. Interphase Cytogenetic Analysis of Micronucleated and Multinucleated Cells Supports the Premature Chromosome Condensation Hypothesis as the Mechanistic Origin of Chromothripsis. Cancers 2019, 11, 1123. [CrossRef] [PubMed]

57. Ly, P.; Brunner, S.F.; Shoshani, O.; Kim, D.H.; Lan, W.; Pyntikova, T.; Flanagan, A.M.; Behjati, S.; Page, D.C.; Campbell, P.J.; et al. Chromosome segregation errors generate a diverse spectrum of simple and complex genomic rearrangements. Nat. Genet. 2019, 51, 705-715. [CrossRef] [PubMed]

58. Ly, P.; Teitz, L.S.; Kim, D.H.; Shoshani, O.; Skaletsky, H.; Fachinetti, D.; Page, D.C.; Cleveland, D.W. Selective $\mathrm{Y}$ centromere inactivation triggers chromosome shattering in micronuclei and repair by non-homologous end joining. Nat. Cell Biol. 2017, 19, 68-75. [CrossRef]

59. Forment, J.V.; Kaidi, A.; Jackson, S.P. Chromothripsis and cancer: Causes and consequences of chromosome shattering. Nat. Rev. Cancer 2012, 12, 663-670. [CrossRef]

60. Waldron, D. Genome stability: Chromothripsis and micronucleus formation. Nat. Rev. Genet. 2015, 16, 376-377. [CrossRef] [PubMed]

61. Okamoto, A.; Utani, K.; Shimizu, N. DNA replication occurs in all lamina positive micronuclei, but never in lamina negative micronuclei. Mutagenesis 2012, 27, 323-327. [CrossRef]

62. Hatch, E.M.; Fischer, A.H.; Deerinck, T.J.; Hetzer, M.W. Catastrophic nuclear envelope collapse in cancer cell micronuclei. Cell 2013, 154, 47-60. [CrossRef]

63. Guo, X.; Dai, X.; Wu, X.; Zhou, T.; Ni, J.; Xue, J.; Wang, X. Understanding the birth of rupture-prone and irreparable micronuclei. Chromosoma 2020. [CrossRef]

64. Mackenzie, K.J.; Carroll, P.; Martin, C.A.; Murina, O.; Fluteau, A.; Simpson, D.J.; Olova, N.; Sutcliffe, H.; Rainger, J.K.; Leitch, A.; et al. cGAS surveillance of micronuclei links genome instability to innate immunity. Nature 2017, 548, 461-465. [CrossRef]

65. de Oliveira Mann, C.C.; Kranzusch, P.J. cGAS Conducts Micronuclei DNA Surveillance. Trends Cell Biol. 2017, 27, 697-698. [CrossRef]

66. Spektor, A.; Umbreit, N.T.; Pellman, D. Cell Biology: When Your Own Chromosomes Act like Foreign DNA. Curr. Biol. 2017, 27, R1228-R1231. [CrossRef] [PubMed]

67. Quek, H.; Luff, J.; Cheung, K.; Kozlov, S.; Gatei, M.; Lee, C.S.; Bellingham, M.C.; Noakes, P.G.; Lim, Y.C.; Barnett, N.L.; et al. A rat model of ataxia-telangiectasia: Evidence for a neurodegenerative phenotype. Hum. Mol. Genet. 2017, 26, 109-123. [CrossRef]

Publisher's Note: MDPI stays neutral with regard to jurisdictional claims in published maps and institutional affiliations.

(C) 2020 by the author. Licensee MDPI, Basel, Switzerland. This article is an open access article distributed under the terms and conditions of the Creative Commons Attribution (CC BY) license (http://creativecommons.org/licenses/by/4.0/). 